\title{
O PAPEL DA DIDÁTICA NA FORMAÇÃO DOS PROFESSORES DE EDUCAÇÃO FÍSICA: A OPINIÃ̃O DOS DISCENTES
}

Andréia Cristina Metzner, Faculdades Integradas Fabibe, Bebedouro, São Paulo - Brasil

\section{RESUMO}

O processo histórico da Educação brasileira mostra que somente no ano de 1969 foram incluídas as matérias pedagógicas na estrutura curricular dos cursos de Licenciatura em Educação Física. Dentre essas matérias pedagógicas encontramos: Didática, Estrutura e Funcionamento do Ensino e, Prática de Ensino/Estágio Supervisionado. A presente pesquisa teve como objetivos discutir o papel da Didática na formação dos professores de Educação Física e verificar a opinião dos alunos sobre essa disciplina. Por meio dos dados obtidos, percebemos que os discentes acreditam que a disciplina de Didática está relacionada as formas de ensinar e que a finalidade dessa disciplina é preparar o futuro professor para a sua atuação pedagógica. Por isso, acreditamos que o papel dessa disciplina para formação profissional precisa ser mais bem discutida nos cursos de licenciatura para que os graduandos possam entender que ser professor é um processo dinâmico onde teoria e prática se completam.

Palavras-Chave: Educação Física; Didática; Formação Profissional.

\section{THE ROLE OF DIDACTICALLY IN THE TRAINING OF TEACHERS OF PHYSICAL EDUCATION: A VIEW OF STUDENTS}

\begin{abstract}
The historical process of Brazilian Education shows that only in 1969 were included educational materials in the structure of curricula of Bachelor in Physical Education. Among these we find pedagogical materials: Curriculum, Structure and Functioning of Teaching and Teaching Practice / Training. This study aimed to discuss the role of the Curriculum in the training of PE teachers and check the students' opinions about this subject. Through the data obtained, we noticed that students believe that the discipline is linked to the didactic methods of teaching and that the purpose of this course is to prepare future teachers for their teaching performance. Therefore, we believe that the role of this discipline for training needs to be further discussed in undergraduate courses for undergraduates can understand that being a teacher is a dynamic process where theory and practice complement each other.
\end{abstract}

Key-Words: Physical Education; Didatics; Occupational training.

Conexões: revista da Faculdade de Educação Física da UNICAMP, Campinas, v. 9, n. 1, p. 166-192, jan./abr. 2011. ISBN: 1983-9030 


\section{INTRODUÇÃO}

O estudo da formação docente, tendo como objeto de discussão o desenvolvimento profissional de professores, mostra-se relevante visto que a literatura traz questões importantes relacionadas aos cursos de licenciatura. Uma dessas questões está relacionada à necessidade de se repensar as disciplinas que compõem o currículo de formação básica, pois as novas exigências da época, principalmente devido as novas tecnologias, buscam um outro tipo de professor.

A formação profissional é um processo pedagógico, intencional e organizado, de preparação teórico-científica e técnica do professor para dirigir competentemente o processo de ensino. ${ }^{1}$

Por isso, ao discutirmos as disciplinas que compõem a grade curricular dos cursos de formação inicial de professores não podemos deixar de ressaltar que a Didática é uma área de estudo cujo foco principal é o processo de ensino ou a ação docente. Portanto, é a disciplina que expressa, dentro da grade curricular, diferentes teorias, tendências e posições na área.

A Didática, definindo-se como mediação dos objetivos e conteúdos do ensino, investiga as condições e formas que vigoram no ensino e, ao mesmo tempo, os fatores reais (sociais, políticos, culturais, psicossociais, etc) condicionantes das relações entre a docência e a aprendizagem.

Conexões: revista da Faculdade de Educação Física da UNICAMP, Campinas, v. 9, n. 1, p. 166-192, jan./abr. 2011. ISBN: 1983-9030 
Dessa forma, a presente pesquisa tem como objetivos discutir o papel da Didática na formação dos professores de Educação Física e verificar a opinião dos discentes sobre essa disciplina.

A abordagem utilizada para a realização desse trabalho foi a pesquisa qualitativa. $\mathrm{O}$ instrumento metodológico utilizado foi um questionário composto por quatro questões abertas.

O questionário foi aplicado numa Instituição Particular de Ensino Superior, localizada no interior do Estado de São Paulo, para 29 alunos do curso de Licenciatura em Educação Física. Após a aplicação do questionário, os dados foram organizados em 3 categorias de análise (Conceito de Didática; Contribuições da Didática para a formação do professor de Educação Física e; A concepção dos alunos sobre a importância dessa disciplina) e foram analisados a partir do referencial teórico do trabalho.

\section{O PAPEL DA DIDÁTICA NA FORMAÇÃO DO PROFISSIONAL DE EDUCAÇÃO FÍSICA}

O curso de Licenciatura em Educação Física prepara o graduando para a atuação em escolas de Educação Básica. De acordo com a Lei de Diretrizes e Bases da Educação Nacional de 20 de Dezembro de 1996, a "Educação Física, integrada à proposta pedagógica da escola, é componente curricular da Educação Básica, ajustando-se as faixas etárias e as condições da população escolar, sendo facultativa nos cursos noturnos". ${ }^{2}$ (art.26 $6^{\circ} \S 3^{\circ}$ ). Portanto, a partir desta data, a Educação Física tornou-se um componente curricular obrigatório em todos os Níveis de Ensino.

Conexões: revista da Faculdade de Educação Física da UNICAMP, Campinas, v. 9, n. 1, p. 166-192, jan./abr. 2011. ISBN: 1983-9030 
Assim, os professores de Educação Física que atuam nas escolas necessitam se impor, saber argumentar, elaborar conteúdos e metodologias coerentes, ministrar atividades diversificadas e mostrar que essa disciplina tem o mesmo valor dos demais componentes curriculares.

Porém, os professores ao se depararem com a realidade escolar, muitas vezes, encontram um universo inteiramente novo. Isso acontece, principalmente, devido a uma formação acadêmica deficiente que não forneceu uma instrumentalização básica necessária para o empreendimento de ações didáticas a serem desenvolvidas nas aulas de Educação Física. ${ }^{3}$

Segundo Borges, ${ }^{3}$ um dos problemas encontrados nos cursos de Educação Física é a distância entre as disciplinas de fundamentos e as disciplinas do campo pedagógico. A mesma autora acrescenta que, além dessa distância, dentro da área denominada pedagógica há uma fragmentação que marca o conteúdo e o ensino de algumas disciplinas, tais como: metodologia de ensino, didática, prática de ensino e estágio supervisionado.

Para que os cursos de Licenciatura em Educação Física possam desenvolver uma formação competente para o professor, além de buscar uma prática transformadora é preciso superar a dicotomia entre as disciplinas pedagógicas das específicas. ${ }^{3}$

Porém, cada vez mais nos cursos de formação, são priorizadas as disciplinas científicas. Segundo Borges ${ }^{3}$ a prática do professor "abarca ações que nem sempre podem ser descritas em livros e que tampouco podem ser prescritas em manuais". Por isso, não basta compreender quais atividades são importantes para o desenvolvimento dos alunos, mas é preciso conhecer diferentes metodologias, saber selecionar conteúdos coerentes, criar estratégias, utilizar recursos diversificados, conseguir elaborar uma seqüência lógica de atividades, vivenciar e Conexões: revista da Faculdade de Educação Física da UNICAMP, Campinas, v. 9, n. 1, p. 166-192, jan./abr. 2011. ISBN: 1983-9030 
observar outros profissionais da área, discutir sobre a relação teoria-prática, conseguir refletir sobre a sua prática pedagógica e etc., visando um ensino eficiente e de qualidade.

Por isso, a Didática é de fundamental importância para os cursos de Licenciatura, inclusive em Educação Física, pois essa disciplina constitui-se de um corpo de conhecimentos sobre o ensino que serve para garantir sua eficiência. ${ }^{4}$ A autora complementa que:

a ação de ensinar é sobretudo uma intenção e indica que na maior parte das vezes há um longo caminho entre o propósito e sua realização. Para tanto, entram em cena procedimentos ditos didáticos, visando um encontro entre o ensinar e o aprender. ${ }^{4}$ (p.15).

A Didática é uma disciplina eminentemente pedagógica e opera a interligação entre teoria e prática. Ela tem como objeto de estudo o processo de ensino na sua globalidade, ou seja, envolve condições e meios de direção, princípios, finalidades, conteúdos, objetivos, métodos e organização do ensino e da aprendizagem. Nesse sentido, podemos entender a Didática como a disciplina que define a direção do processo de ensinar e unifica a atividade teórica e a atividade prática. $^{5}$

Segundo Haidt ${ }^{6}$ (p.13) "enquanto a Pedagogia pode ser conceituada como a ciência e a arte da educação, a Didática é definida como a ciência e a arte do ensino”.

Ensinar e aprender são como as duas faces de uma mesma moeda. Dessa forma, o ensino, que é o objeto de estudo da Didática, não pode ser tratado apenas levando em consideração o professor, mas também, deve-se considerar a aprendizagem por parte do aluno. A Didática é o estudo do processo de ensino e aprendizagem e, portanto, enfatiza a relação professor-aluno (HAIDT, 2002).

Conexões: revista da Faculdade de Educação Física da UNICAMP, Campinas, v. 9, n. 1, p. 166-192, jan./abr. 2011. ISBN: 1983-9030 
A evolução histórica da Didática nos mostra que até o início do século XIX, predominou-se na prática escolar uma aprendizagem do tipo passivo e receptivo, ou seja, aprender era basicamente memorizar. Essa forma de ensino baseava-se na concepção de que o aluno era como um papel em branco sem nada escrito onde tudo podia ser impresso. O importante nessa forma de aprendizagem era que o aluno reproduzisse literalmente as frases e palavras decoradas. $^{6}$

Ao longo dos séculos, os filósofos e educadores visando tornar o ensino mais estimulante e adaptado aos interesses dos alunos, criaram algumas teorias que tentavam explicar como o ser humano é capaz de apreender e assimilar o mundo que o circunda. Com base nessas teorias do conhecimento, alguns princípios didáticos foram formulados, tais como: Sócrates (século V a.C.) acreditava que o saber, o conhecimento, é uma descoberta que a própria pessoa realiza, portanto, a função do mestre é apenas ajudar o discípulo descobrir, por si mesmo, a verdade; Comenius (1592-1670) valorizava o processo indutivo como sendo a melhor forma de chegar ao conhecimento generalizado; Pestalozzi (1746-1827) defendia a doutrina dos naturalistas que acreditava que o ser humano nascia bom e que o caráter de um homem era formado pelo ambiente que o rodeia. Herbart (1776-1841) dizia que a característica fundamental do ser humano era a sua capacidade de assimilação, portanto, ao nascer o ser humano não é bom e nem mau, mas irá desenvolver para um lado ou para o outro a partir das influências externas, das representações formadas e de suas combinações; Dewey (1859-1952) mostra que o conhecimento e o ensino devem estar intimamente relacionados à ação, à vida prática, à experiência, ou seja, o saber é um meio para ajudar o homem na sua existência, na sua vida prática. Esses educadores e filósofos, bem como outros pensadores, defenderam a necessidade de se rever os processos de ensino e aprendizagem, por isso suas obras representam Conexões: revista da Faculdade de Educação Física da UNICAMP, Campinas, v. 9, n. 1, p. 166-192, jan./abr. 2011. ISBN: 1983-9030 
verdadeiros marcos que repercutiram diretamente no campo da Didática, principalmente, pelo fato de todos esses educadores tentarem fazer com que a reforma do ensino não ficasse restrita a uma elite, mas fosse estendida a parcelas cada vez maiores da população. Ou seja, eles acreditavam na educação popular. ${ }^{6}$

No dias atuais, como a sociedade é uma realidade em constante transformação, é inevitável o repensar contínuo da Educação, do homem, da escola e, consequentemente, da Didática. ${ }^{7}$

Para que a concepção de Educação ou de Didática não envelheçam, é preciso analisar, constantemente, sob nova luz, os conceitos conhecidos e a prática social atual, ou seja, é preciso refletir regularmente a respeito das ações e estratégias desenvolvidas no cotidiano escolar, tendo como referência as mudanças percebidas na sociedade. ${ }^{7}$

Hoje, de acordo com Libâneo, ${ }^{5}$ (2006), o mundo contemporâneo exige dos educadores novos objetivos, novas habilidades cognitivas, mais capacidade de pensamento abstrato e flexibilidade de raciocínio, capacidade de percepção de mudanças. Portanto, é necessário que esses profissionais tenham uma formação geral e profissional para além de suas especialidades, ou seja, deve-se estar presente nos currículos de formação inicial e continuada disciplinas voltadas ao repensar dos processos de aprendizagem e das formas do aprender a aprender.

\section{A FORMAÇÃO PROFISSIONAL DO PROFESSOR}

A formação profissional do professor é realizada nos cursos de Pedagogia e nas diversas Licenciaturas, como por exemplo, nas Licenciaturas em Educação Física. Segundo Libâneo ${ }^{1}$

Conexões: revista da Faculdade de Educação Física da UNICAMP, Campinas, v. 9, n. 1, p. 166-192, jan./abr. 2011. ISBN: 1983-9030 
(p.27), “formação profissional é um processo pedagógico, intencional e organizado, de preparação teórico-científica e técnica do professor para dirigir competentemente o processo de ensino".

A formação do professor abrange duas dimensões: a formação acadêmica específica nas disciplinas em que o docente irá se especializar e a formação pedagógica que envolve os conhecimentos da Filosofia, Psicologia da Educação, Sociologia, História da Educação e da própria Didática. ${ }^{1}$

Libâneo ${ }^{1}$ acredita que a formação profissional para o magistério requer uma sólida formação teórico-prática, portanto, a Didática se caracteriza como mediação entre as bases teóricocientíficas da educação escolar e a prática docente, pois os conteúdos das disciplinas específicas precisam ligar-se às exigências metodológicas e aos problemas e desafios da prática. O autor complementa que:

O domínio das bases teórico-científicas e técnicas, e sua articulação com as exigências concretas do ensino, permitem maior segurança profissional, de modo que o docente ganhe base para pensar sua prática e aprimore sempre mais a qualidade do seu trabalho. ${ }^{1}$ (p. 28).

Segundo Pimenta, ${ }^{8}$ pesquisas têm demonstrado que os cursos de formação de professores pouco tem contribuído com a formação da identidade do profissional docente. A autora acrescenta que além de proporcionar uma habilitação legal para o exercício profissional docente, os cursos de formação inicial têm a finalidade de formar o professor ou colaborar com a sua formação.

Conexões: revista da Faculdade de Educação Física da UNICAMP, Campinas, v. 9, n. 1, p. 166-192, jan./abr. 2011. ISBN: 1983-9030 
Podemos constatar que, no mundo contemporâneo, o crescimento quantitativo dos sistemas de ensino não tem correspondido a uma melhoria qualitativa na formação dos alunos. Isso mostra a importância de definir uma nova identidade profissional do professor e a disciplina de Didática, nos cursos de Licenciatura, se propõe a mediar esse processo de construção de identidade dos futuros professores.

Os alunos quando chegam ao curso de formação inicial trazem consigo saberes sobre o que é ser professor. Esses saberes fazem parte de sua experiência de aluno que durante a sua trajetória escolar esteve em contato com diferentes professores. Por meio dessas experiências o aluno é capaz de dizer quais foram os bons professores, quais dominavam os conteúdos, quais não sabiam ensinar, quais professores foram significativos em suas vidas, enfim, quais foram aqueles e de que forma eles contribuíram com a sua formação humana. Por isso, Pimenta $^{8}$ (p.20) afirma que o desafio dos cursos de formação inicial é "o de colaborar no processo de passagem dos alunos de seu ver o professor como aluno ao seu ver-se como professor". Isto é, de construir a sua identidade de professor, e para isso, os saberes da experiência não bastam.

Aliados á experiência é preciso ter uma preparação científica, técnica e social. Portanto, o segundo passo no processo de construção da identidade dos professores no curso de licenciatura é discutir a questão dos conhecimentos nos quais são especialistas (história, geografia, matemática, educação física, etc.) no contexto da contemporaneidade. ${ }^{8}$

O professor precisa ter domínio dos conhecimentos específicos de sua área e, dentre outras coisas, os professores precisam saber: quais conceitos devem ser ensinados, como esses Conexões: revista da Faculdade de Educação Física da UNICAMP, Campinas, v. 9, n. 1, p. 166-192, jan./abr. 2011. ISBN: 1983-9030 
conceitos foram construídos, quais são as idéias mais importantes e os princípios básicos desses conteúdos/disciplinas, quais são os melhores exemplos, qual a importância da disciplina e de seu conteúdo para os alunos, por que esses conteúdos estão sendo propostos para esse nível de ensino, etc. ${ }^{9}$

A representação de uma disciplina depende do conhecimento dos conteúdos em um nível de profundidade, pois se o professor não conhece bem o conteúdo que precisa ensinar, provavelmente, o ensinará de forma superficial aos alunos.

O terceiro passo é reconhecer que para saber ensinar não basta a experiência e os conhecimentos específicos, mas se fazem necessários os saberes pedagógicos e didáticos. Porém, na história da formação dos professores, esses saberes têm sido trabalhados como blocos distintos e desarticulados. $^{8}$

No caso da Educação Física, as disciplinas específicas se sobrepõem às disciplinas pedagógicas, em decorrência do status e poder que a área de Ciências Biológica adquire na academia. As disciplinas mais "temidas" e consideradas importantes pelos graduandos são Fisiologia, Cinesiologia, Treinamento Desportivo e as diferentes Modalidades Esportivas. Esses alunos não percebem que, ao atuar no ambiente escolar, os saberes científicos só terão valor se forem vinculados com os saberes pedagógicos.

O saber pedagógico, segundo Azzi ${ }^{10}$ (p.43) é “o saber que o professor constrói no cotidiano de seu trabalho e que fundamenta sua ação docente", ou seja, o saber construído pelo professor

Conexões: revista da Faculdade de Educação Física da UNICAMP, Campinas, v. 9, n. 1, p. 166-192, jan./abr. 2011. ISBN: 1983-9030 
no exercício da docência e elaborado a partir do conhecimento e/ou saber que o professor possui.

Segundo Pimenta ${ }^{11}$ o saber pedagógico se elabora, na prática de cada professor, na "química" que faz entre teoria e prática.

Por isso, os cursos de formação inicial devem contribuir com os saberes pedagógicos dos alunos colocando à sua disposição pesquisas sobre a atividade docente escolar e, ao mesmo tempo, procurar desenvolver com eles pesquisas sobre a realidade escolar. Ou seja, é importante que as disciplinas pedagógicas promovam o conhecimento direto ou indireto das realidades escolares e os sistemas de ensino, para que os discentes possam começar a olhar, ver e analisar o dia-a-dia da escola com olhos não mais de alunos, mas de futuros professores. $^{8}$

Acreditamos que o professor aprende muito mais com a reflexão que faz sobre si, os alunos, os conhecimentos, as práticas, os valores, os objetivos educacionais, a proposta pedagógica da escola, etc. Por isso, as disciplinas pedagógicas, dentre elas a Didática, são importantes nos cursos de formação de professores.

Porém, nos cursos de preparação docente, a Didática tem se debatido com expectativas em torno dessa disciplina que vão além de suas reais possibilidades onde, muitas vezes, lhe é atribuída a tarefa de dotar o indivíduo de meios, regras e procedimentos que o habilitem a ter garantias de êxito no exercício de sua função. ${ }^{12}$

Conexões: revista da Faculdade de Educação Física da UNICAMP, Campinas, v. 9, n. 1, p. 166-192, jan./abr. 2011. ISBN: 1983-9030 
Pensando sobre as peculiaridades da Didática, Catani, ${ }^{12}$ expressa o seguinte problema: como se ensina a ensinar?

Ao refletir sobre essa questão, a autora mostra que o próprio modo de concebermos o ensino leva-nos a procurarmos na Didática, formas de habilitar o futuro professor quanto aos modos de proceder na situação de ensino. Porém, não existem fórmulas e nem procedimentos únicos a serem reproduzidos no trabalho docente. A Didática deve ser entendida como a disciplina capaz de auxiliar o processo de compreensão das formas de educar. ${ }^{12}$

Portanto, nos cursos de formação de professores, a disciplina de Didática, deve introduzir o indivíduo na compreensão sobre os modos de ensinar, aprender e compreender a realidade.

Dessa forma, acreditamos essa disciplina é fundamental nos cursos de licenciatura em Educação Física, pois através dela é possível estabelecer uma relação entre os conhecimentos científicos e as experiências provenientes da prática profissional.

\section{A CONCEPÇÃO DOS DISCENTES MEDIANTE SEU CURSO DE FORMAÇÃO}

A formação profissional é um conceito que tem evoluído bastante nas últimas décadas. De um modo geral, houve uma evolução de vários elementos tais como: o próprio conceito de formação profissional, a clientela atingida, as entidades que realizam a formação e os conteúdos de aprendizagem. $^{13}$

A área de Educação Física apresenta um mercado de trabalho bastante dinâmico e, por isso, os cursos de formação profissional em Educação Física são divididos em duas áreas: Licenciatura e Bacharelado. A Licenciatura prepara professores para atuar na Educação Conexões: revista da Faculdade de Educação Física da UNICAMP, Campinas, v. 9, n. 1, p. 166-192, jan./abr. 2011. ISBN: 1983-9030 
Básica (Educação Infantil, Ensino Fundamental e Ensino Médio), ou seja, na Educação Formal. Já o Bacharelado, prepara profissionais para atuar no contexto não-escolar, ou seja, em clubes, academias, hotéis, indústrias, etc.

Portanto, de acordo com Betti, ${ }^{14}$ é imprescindível que as faculdades não partam de modelos de currículos pré-fabricados, mas ajustem seus cursos às características da clientela, disponibilidade docente e material. $\mathrm{O}$ autor acrescenta que, além disso, deve-se considerar o mercado de trabalho para que os recursos não sejam investidos de maneira irresponsável.

Desde a década de 60, segundo Silva et al. ${ }^{15}$ (2006) o assunto currículo vem sendo objeto de um amplo processo de discussão. Hoje, após diversas modificações, foram aprovadas em 18 de fevereiro de 2004 as novas Diretrizes Curriculares Nacionais para os Cursos de Graduação em Educação Física.

Segundo Silva et al. ${ }^{15}$ essas Diretrizes Curriculares foram criadas com

a intenção de possibilitar para o graduando a transformação da compreensão sobre o mundo vivido, oportunizar a construção de conhecimentos significativos que se reorganizam em forma de teorias, experiências, habilidades, competências e atitudes. (p. 162)

Em relação à estrutura e organização curricular dos cursos de graduação em Educação Física, de acordo com as Diretrizes Curriculares, cabe à Instituição de Ensino Superior articular as unidades de conhecimento de formação específica e ampliada. ${ }^{16}$

A formação ampliada deverá contemplar as seguintes dimensões do conhecimento: Relação ser humano-sociedade; Biológica do corpo humano e; Produção do conhecimento científico e

Conexões: revista da Faculdade de Educação Física da UNICAMP, Campinas, v. 9, n. 1, p. 166-192, jan./abr. 2011. ISBN: 1983-9030 
tecnológico. E a formação específica deverá ampliar as seguintes dimensões: Culturais do movimento humano; Técnico-instrumental e; Didático-pedagógica. ${ }^{16}$

Apesar dos avanços em relação a estruturação da grade curricular dos cursos de formação em Educação Física, ainda muitas modificações precisam ser feitas para podermos atingir um modelo de currículo condizente com as reais necessidades do seu tempo histórico.

Uma das questões a ser repensada diz respeito ao isolamento das disciplinas e professores envolvidos. Segundo Nascimento ${ }^{13}$ “parece existir uma hierarquia na qualidade das pesquisas, de acordo com o tipo de abordagem adotada, que, por sua vez, se vai refletir em sentimentos de inferioridade e superioridade de pontos de vista dos docentes" (p.62). E em relação as disciplinas, o autor mostra que o sistema de créditos ou de matrícula por disciplina, adotados por Instituições de Ensino Superior, favorece a fragmentação curricular, acentuando o trabalho individual do professor com a sua própria disciplina e não de forma integrada com as demais disciplinas.

De modo geral, esses problemas encontrados não são específicos de uma determinada instituição ou curso, mas comuns a maior parte deles. Para Nascimento ${ }^{13}$ eles variam, com maior ou menor intensidade, conforme as características de cada instituição.

A heterogeneidade e fragmentação da grade curricular dos Cursos Superiores dificultam as transferências e os intercâmbios de alunos e, além disso, prejudica o reconhecimento da própria profissão. $^{13}$

Conexões: revista da Faculdade de Educação Física da UNICAMP, Campinas, v. 9, n. 1, p. 166-192, jan./abr. 2011. ISBN: 1983-9030 
Por isso, discutir dilemas e diversas questões referente a formação inicial do professor de Educação Física buscando melhorar a qualidade na preparação desses profissionais torna-se, atualmente, de fundamental importância para o crescimento e valorização da área.

Portanto, a seguir, discutiremos a disciplina Didática nos cursos de Licenciatura em Educação Física e a visão dos alunos sobre essa disciplina.

\section{A didática e a concepção dos discentes}

Todo o processo de formação de professores inclui componentes curriculares voltados a sistematização do "que fazer" educativo, ou seja, da prática pedagógica. Entre eles, de acordo com Candau, a Didática ocupa um lugar de destaque.

Segundo Medeiros, ${ }^{18}$ esta disciplina tem características especiais que a diferencia das demais disciplinas do curso. Essas diferenças não dizem respeito apenas à carga horária, mas, principalmente, pelo fato de recair sobre a Didática a responsabilidade de rever o conteúdo visto pelo aluno durante o curso estabelecendo uma ligação deste com a prática escolar. Além disso, a disciplina de Didática é responsável por garantir espaço para a discussão de questões referentes ao processo de ensino e aprendizagem.

No curso de Licenciatura em Educação Física da faculdade pesquisada, a disciplina Didática acontece no $2^{\circ}$ semestre, isto é, no $1^{\circ}$ ano do curso. Esta disciplina tem uma carga horária de 80 horas que são distribuídas em quatro aulas semanais.

Conexões: revista da Faculdade de Educação Física da UNICAMP, Campinas, v. 9, n. 1, p. 166-192, jan./abr. 2011. ISBN: 1983-9030 
No ano de 2008 foram matriculados, nessa disciplina, um total de 29 alunos. Conforme a metodologia apresentada na introdução, todos esses alunos participaram da presente pesquisa e responderam um questionário composto por quatro questões abertas.

Para uma melhor visualização dos resultados obtidos, foram elaboradas 3 categorias de análise onde são destacados trechos das respostas dos alunos que são pertinentes a essa pesquisa, bem como a respectiva análise.

As três categorias englobam, basicamente, os seguintes tópicos: 1-) Conceito de Didática; 2-) Contribuições da Didática para a formação do professor de Educação Física e; 3-) A concepção dos alunos sobre a importância dessa disciplina.

Como forma de preservar o nome dos alunos participantes da pesquisa, assim como manter sigilo da instituição a qual pertencem, procuramos denominá-los aleatoriamente neste trabalho, por meio de números, como por exemplo, aluno 1, 2, 3, 4 e etc.

\section{Conceito de didática}

A partir dos dados coletados foi possível observar que quase $100 \%$ dos alunos acreditam que o conceito de Didática está relacionado a forma de ensinar.

Com relação às respostas dos participantes da pesquisa sobre o que eles entendem por Didática, destacamos:

"Acredito que seja algo relacionado a educação, ao modo de se ensinar, trabalhar com os alunos" (Participante 10).

Conexões: revista da Faculdade de Educação Física da UNICAMP, Campinas, v. 9, n. 1, p. 166-192, jan./abr. 2011. ISBN: 1983-9030 
"Não tenho nenhum conhecimento do que é Didática, mas acho que é uma matéria que vai nos ensinar como dar uma boa aula para nossos alunos" (Participante 12).

"Didática são as várias formar de se ensinar um mesmo conteúdo em diferentes situações” (Participante 13).

"Acho que a Didática é um modo de ensinar os alunos, uma forma de ensinar os professores a dar aula, etc.” (Participante 19).

"Didática é o saber lidar com situações complicadas dentro e fora de seu trabalho" (Participante 27).

De acordo com as respostas retiradas dos questionários aplicados aos alunos, podemos perceber que a disciplina Didática está relacionada a busca por uma "receita pronta" e pela forma correta de ensinar.

Essas respostas deixam evidente o caráter instrumental da Didática, ou seja, os alunos entendem essa disciplina como um conjunto de procedimentos e técnicas que o professor deve dominar para promover um ensino eficiente.

Porém, segundo Candau, ${ }^{17}$ essa visão instrumental da Didática precisa ser superada e para isso essa disciplina deve assumir o caráter multidimensional do processo de ensino-aprendizagem e colocar a articulação das três dimensões (técnica, humana e política) no centro configurador de sua temática.

Nessa perspectiva, o desafio do momento é superar a Didática exclusivamente instrumental e construir uma Didática fundamental. Ou seja, a reflexão didática deve partir do compromisso com a transformação social, com a busca de práticas pedagógicas que tornem o ensino de fato eficiente, com o rompimento de uma prática profissional individualista, com a promoção do trabalho em comum de professores e especialista, com a busca de formas de aumentar a Conexões: revista da Faculdade de Educação Física da UNICAMP, Campinas, v. 9, n. 1, p. 166-192, jan./abr. 2011. ISBN: 1983-9030 
permanência das crianças na escola, com a discussão de questões curriculares e a sua interação concreta com a população e suas exigências, enfim, deve-se refletir a analisar as experiências concretas procurando trabalhar continuamente a relação teoria-prática. ${ }^{17}$

Segundo Libâneo ${ }^{1}$ a Didática:

Investiga os fundamentos, condições e modos de realização da instrução e do ensino. A ela cabe converter objetivos sócios-políticos e pedagógicos em objetivos de ensino, selecionar conteúdos e métodos em função desses objetivos, estabelecer os vínculos entre ensino e aprendizagem, tendo em vista o desenvolvimento das capacidades mentais dos alunos. (p. 25-26)

Dessa forma, o conceito de Didática vai além das formas de ensinar, pois a mesma se caracteriza como a mediação entre as bases teórico-científicas da educação escolar e a prática docente.

\section{Contribuições da didática para a formação do professor de Educação Física}

A segunda categoria de análise elaborada diz respeito às contribuiçõos da Didática para a formação do professor de Educação Física. Dentre as respostas obtidas encontramos:

"O papel da Didática é muito importante, pois acredito que seja assim que iremos aprender nosso modo de se comportar e se impor perante uma sala de aula" (Participante 10).

"A didática, se for o que eu acho que é, é algo importante, já que temos que saber como ser um bom profissional, educando os alunos de maneira certa" (Participante 12).

"É importante porque proporciona situações adversas de ensino" (Participante 13).

"A Didática é muito importante para a formação não só para Educação Física, mas para qualquer tipo de profissional da educação, pois é com a Didática que se aprende a como lidar com diversas situações dentro de uma sala de aula" (Participante 14).

"Capacitar os professores a terem competências para ensinar" (Participante 19).

Conexões: revista da Faculdade de Educação Física da UNICAMP, Campinas, v. 9, n. 1, p. 166-192, jan./abr. 2011. ISBN: 1983-9030 
Os participantes da pesquisa acreditam que a finalidade do ensino da Didática é preparar o futuro professor para a sua atuação pedagógica. E a maioria dos participantes espera uma "receita pronta" de como ser um bom professor. Ou seja, eles afirmam, em suas respostas, que a Didática está relacionada ao saber ensinar, ou seja, ter didática significa saber ensinar.

Diante disso, Pimenta $^{8}$ afirma que essa percepção atribuída a Didática mostra que os alunos esperam que essa disciplina lhes forneça as técnicas a serem aplicadas em toda e qualquer situação para que o ensino dê certo.

Essa concepção sobre o papel da Didática na formação dos professores, de acordo com Candau, ${ }^{17}$ acontece porque na maioria dos cursos de licenciatura, o seu conteúdo constitui um conjunto de informações fragmentadas, não há uma articulação entre a teoria e a prática, caracteriza-se pelo consumismo de teorias importadas e, além disso, desenvolve-se sem articulação com as demais disciplinas.

Por isso, os graduandos dos cursos de Licenciatura, no caso de Educação Física, não conseguem definir adequadamente o papel dessa disciplina para a sua formação.

Segundo André ${ }^{19}$ a Didática, nos cursos de formação inicial, tem como preocupações básicas:

A multidimensionalidade do processo ensino-aprendizagem, ressaltando a necessidade de articular as dimensões humana, técnica e sociopolítica do fenômeno educativo; b) a contextualização da prática pedagógica; c) a explicação e análise dos pressupostos que fundamentam as diferentes abordagens de ensino; e d) a reflexão sobre experiências concretas, procurando trabalhar continuamente a relação teoria-prática. (p. 197)

Conexões: revista da Faculdade de Educação Física da UNICAMP, Campinas, v. 9, n. 1, p. 166-192, jan./abr. 2011. ISBN: 1983-9030 
Portanto, para que essa nova visão de didática possa vir a se concretizar e ser realmente compreendida e valorizada pelos discentes é preciso que haja uma busca sistemática para definição do objeto da didática, que seja feita uma análise critica dos conteúdos abordados na disciplina de didática, e que se procure articular o discurso em sala de aula com a realidade vivida no dia-a-dia da prática educativa. ${ }^{19}$

\section{A concepção dos alunos sobre a importância dessa disciplina}

A concepção dos discentes sobre como o seu curso de formação considera e trabalha com a questão da importância da Didática para a formação do profissional de Educação Física gerou esta $3^{\text {a }}$ categoria de análise. Vejamos algumas respostas apresentadas pelos alunos:

"O curso mostra que a Didática é uma disciplina muito importante e abrange o conhecimento de todos que estão ligados no curso procurando formar bons profissionais" (Participante 5).

"Na minha opinião, ele se preocupa muito em formar profissionais bem capacitados, em nos mostrar muitos meios para tornar as aluas mais apreciadas pelos alunos. E o mais importante é que mesmo sendo professores de educação Física, não podemos ter a cabeça vazia, temos que ter muito conhecimento sobre vários assuntos também" (Participante 10).

"Com certeza é importante, afinal no nosso curso de licenciatura, todas as matérias nos ensinam a ser professores” (Participante 12).

"Bom, eu acho que é valorizado este assunto "didática”, pois muitas matérias notamos a sua presença. A preocupação com a forma de ensino é muito usada em todas as outras disciplinas" (Participante $18)$.

"Percebo que os professores estão sempre preocupados em nos orientar em relação a questão da educação e da ética. E com a questão de como lidar com diferentes situações em sala de aula” (Participante 23).

Conexões: revista da Faculdade de Educação Física da UNICAMP, Campinas, v. 9, n. 1, p. 166-192, jan./abr. 2011. ISBN: 1983-9030 
Podemos notar, nas respostas dos discentes, que eles acreditam que o seu curso de formação trabalha a questão da importância da Didática de forma eficiente. Além disso, a busca em formar profissionais capacitados e a preocupação em relacionar a teoria e a prática parece fazer parte de todas as disciplinas pertencentes à grade curricular.

Apesar desses alunos não conseguirem descrever claramente a forma como o seu curso lida com a questão da importância da Didática para a sua formação profissional em Educação Física, podemos perceber que os mesmos estão satisfeitos com os seus professores e com a forma que eles estruturam a suas disciplinas.

Segundo Rangel ${ }^{20}$ é muito importante que o conhecimento gerado dentro das Universidades se aproxime da prática do professor fornecendo alternativas aos problemas do dia-a-dia escolar. Por isso, quando os discentes relatam que os professores do curso se preocupam em formar bons profissionais, provavelmente, a relação entre teoria e prática está sendo trabalhada de forma satisfatória em suas disciplinas.

Os cursos de formação profissional em Educação Física foram criados predominantemente por militares, que ao lado dos médicos foram os primeiros a advogar a importância da prática de atividades físicas, embora com objetivos distintos. Na década de 80, com a implantação dos cursos de Pós-graduação em Educação Física e o questionamento da identidade da área, inicia-se uma nova concepção curricular que acarretou algumas mudanças significativas. Uma dessas mudanças foi a ênfase nas disciplinas teóricas, ou seja, do "saber fazer" passou-se ao "saber ensinar". 21

Conexões: revista da Faculdade de Educação Física da UNICAMP, Campinas, v. 9, n. 1, p. 166-192, jan./abr. 2011. ISBN: 1983-9030 
A busca pela articulação entre teoria e prática visa fornecer subsídios para que o graduando possa compreender os processos de ensino e aprendizagem. Por isso, acreditamos que o maior desafio que se coloca hoje é superar a dicotomia entre a teoria e prática, que distancia as disciplinas pedagógicas dos cursos de Licenciatura e a formação profissional do mercado de trabalho.

Portanto, os depoimentos apresentados pelos discentes evidenciam que, além de conteúdos teóricos, a busca por questões práticas, éticas e de conhecimentos gerais são consideradas importantes para sua formação inicial. Assim, de acordo com Hunger e Ferreira $^{22}$, os cursos de licenciatura devem "superar a concepção de prática como aplicação de teoria, entendendo-a, portanto, como uma dimensão do conhecimento que deve estar presente tanto na reflexão sobre a atividade profissional quanto no exercício da mesma” (p.143).

\section{CONSIDERAÇÕES FINAIS}

A Didática é uma disciplina eminentemente pedagógica e opera a interligação entre teoria e prática. Ela tem como objeto de estudo o processo de ensino na sua globalidade, ou seja, envolve condições e meios de direção, princípios, finalidades, conteúdos, objetivos, métodos e organização do ensino e da aprendizagem.

Nesse sentido, podemos entender a Didática como a disciplina que define a direção do processo de ensinar e unifica a atividade teórica e a atividade prática.

Assim, a presente pesquisa teve como objetivos discutir o papel da Didática na formação dos professores de Educação Física e verificar a opinião dos discentes sobre essa disciplina.

Conexões: revista da Faculdade de Educação Física da UNICAMP, Campinas, v. 9, n. 1, p. 166-192, jan./abr. 2011. ISBN: 1983-9030 
Podemos perceber, por meio dos dados obtidos, que os discentes acreditam que a disciplina de Didática está relacionada as formas de ensinar e que a finalidade dessa disciplina é preparar o futuro professor para a sua atuação pedagógica.

Essa responsabilidade que os discentes atribuem a essa disciplina, provavelmente, deve-se ao fato deles acreditarem que "ter didática é saber ensinar". Além disso, a maioria dos participantes da pesquisa espera uma "receita pronta" de como ser um bom professor.

Vimos, na revisão de literatura, que a tarefa da Didática é muito mais do que dotar o indivíduo de meios, regras e procedimentos que o habilitem a ter garantias de êxito no exercício de sua função. Hoje, nos cursos de preparação docente, ela deve ser entendida como a disciplina capaz de auxiliar o processo de compreensão das formas de educar.

Ao questionarmos os discentes sobre a como o seu curso de formação considera e trabalha com a questão da importância da Didática para a formação do profissional de Educação Física obtivemos respostas positivas em relação aos professores do curso e a forma desses ministrarem suas disciplinas.

Os discentes não definiram claramente a forma que o seu curso trabalha com a questão da importância da Didática para a sua formação profissional, porém, ao estarem satisfeitos com o curso e com os seus professores, acreditamos que essa valorização esteja acontecendo de forma implícita.

A preocupação pela formação de bons profissionais, baseados nos relatos dos discentes, parece estar presente em todas as disciplinas pertencentes ao curso de Licenciatura em Conexões: revista da Faculdade de Educação Física da UNICAMP, Campinas, v. 9, n. 1, p. 166-192, jan./abr. 2011. ISBN: 1983-9030 
Educação Física da Instituição pesquisada. Isso é muito importante para o avanço dessa área, pois a disciplina de Educação Física, em muitas escolas, é desvaloriza e concebida como desnecessária.

Por isso, os discentes precisam compreender que a Educação Física, mesmo utilizando recursos específicos e espaços diferenciados, tais como: quadras, áreas abertas, campos, bolas, cordas e etc., ela deve ser tão respeitada quanto as outras disciplinas do currículo escolar. Essa questão e muitas outras encontradas no dia-a-dia da escola e envolvendo a prática pedagógica dos professores podem e devem ser discutidas na disciplina de Didática nos cursos de formação inicial já que a mesma se constitui num importante espaço de discussão e num poderoso instrumento de mudança na prática educativa dos futuros professores. Por isso, acreditamos que ao compreender a importância dessa disciplina para a sua formação profissional, o graduando em Licenciatura em Educação Física, entenderá que ser professor é um processo dinâmico onde teoria e prática se completa.

Portanto, a Didática bem como as demais disciplinas pedagógicas devem ser concebidas como um núcleo integrador de todos os conteúdos e em todos os momentos que constituem a formação do professor.

\section{REFERÊNCIAS}

${ }^{1}$ LIBÂNEO, J. C. Didática. São Paulo: Cortez, 1994.

${ }^{2}$ BRASIL. Ministério da Educação e Cultura. Lei de Diretrizes e Bases da Educação Nacional. Brasília, 1996.

Conexões: revista da Faculdade de Educação Física da UNICAMP, Campinas, v. 9, n. 1, p. 166-192, jan./abr. 2011. ISBN: 1983-9030 
${ }^{3}$ BORGES, C. M. F. O professor de Educação Física e a construção do saber. Campinas: Papirus, 1998. (Coleção Magistério: Formação e trabalho Pedagógico).

${ }^{4}$ CASTRO, A. D. O ensino: objeto da didática. In: CASTRO, A. D.; CARVALHO, A. M. P. (Org.). Ensinar a ensinar: didática para a escola fundamental e média. São Paulo: Thomson Learning, 2006.

${ }^{5}$ LIBÂNEO, J. C. Educação: pedagogia e didática - o campo investigativo da pedagogia e da didática no Brasil: esboço histórico e buscas de identidade epistemológica e profissional. In: PIMENTA, S. G. (Org.). Didática e formação de professores: percursos e perspectivas no Brasil e em Portugal. 4. ed. São Paulo: Cortez, 2006. p. 77-129.

${ }^{6}$ HAYDT, R. C. C. Curso de didática geral. 7. ed. São Paulo: .Ática, 2002.

${ }^{7}$ PENIN, S. T. S. Didática e Cultura: o ensino comprometido com o social e a contemporaneidade. In: CASTRO, A D.; CARVALHO, A M. P. (Org.). Ensinar a e Ensinar: didática para a escola fundamental e média. São Paulo: Thomson Learning, 2006.

${ }^{8}$ PIMENTA, S. G. Formação de professores: identidade e saberes da docência. In:

(Org). Saberes pedagógicos e atividade docente. 4. ed. São Paulo: Cortez, 2005. p. 15-34.

${ }^{9}$ MIZUKAMI, M. G. N. Aprendizagem da docência: algumas contribuições de L. S. Shulman. Revista Educação Especial, v. 29, n. 2. 2004. Disponível em: <www.ufsm.br/ce/revista/revce/2004/02/r3.htm> . Acesso em: 26 set. 2008.

Conexões: revista da Faculdade de Educação Física da UNICAMP, Campinas, v. 9, n. 1, p. 166-192, jan./abr. 2011. ISBN: 1983-9030 
${ }^{10}$ AZZI, S. Trabalho docente: autonomia didática e construção do saber 4. ed. São Paulo: Cortez, 2005. p. 35-60.

${ }^{11}$ PIMENTA, S. G. Para uma re-significação da didática - ciências da educação, pedagogia e didática (uma revisão conceitual e uma síntese provisória). In: (Org.). Didática e formação de professores: percursos e perspectivas no Brasil e em Portugal. 4. ed. São Paulo: Cortez, 2006. p. 19-76.

${ }^{12}$ CATANI, D. B. A Didática como Iniciação: uma alternativa no processo de formação de professores. In: CASTRO, A. D.; CARVALHO, A. M. P. (Org.). Ensinar a ensinar: didática para a escola fundamental e média. São Paulo: Thomson Learning, 2006.

${ }^{13}$ NASCIMENTO, J. V. Formação do profissional de Educação Física e as novas diretrizes: reflexões sobre a reestruturação curricular. In: SOUZA NETO, S.; HUNGER, D. (Org.). Formação profissional em Educação Física: estudos e pesquisas. Rio Claro: Biblioética, 2006. p. 59-75.

${ }^{14}$ BETTI, M. Perspectivas na formação profissional. In: MOREIRA, W. (Org.). Educação Física \& esportes: perspectivas para o século XXI. Campinas: Papirus, 1992. p. 239-254.

${ }^{15}$ SILVA, S. A. P. S. et al. Análise da nova proposta curricular do curso de Educação Física da Universidade São Judas Tadeu frente às Diretrizes Curriculares Nacionais e CONFEF. In: SOUZA NETO, S.; HUNGER, D. (Org.). Formação Profissional em Educação Física: estudos e pesquisas. Rio Claro: Biblioética, 2006. p. 159-171.

Conexões: revista da Faculdade de Educação Física da UNICAMP, Campinas, v. 9, n. 1, p. 166-192, jan./abr. 2011. ISBN: 1983-9030 
${ }^{16}$ BRASIL. Conselho Nacional de Educação/Câmara do Ensino Superior. Parecer CNE/CES $\mathbf{n}^{\mathbf{0}}$ 0058/2004, de 18 de fevereiro de 2004: diretrizes curriculares nacionais para os cursos de graduação em Educação Física.

${ }^{17}$ CANDAU, V. M. A didática e a formação de educadores - da exaltação à negação: a busca da relevância. In: . (Org). A didática em questão. 6. ed. Petrópolis: Vozes, 1987. p. $12-22$.

${ }^{18}$ MEDEIROS, M. Didática e prática de ensino da Educação Física: para além de uma abordagem formal. Goiânia: Ed. UFG, 1998.

${ }^{19}$ ANDRÉ, M. E. D. A. Tendências no ensino de didática no Brasil. In: PIMENTA, S. G. (Org.). Didática e formação de professores: percursos e perspectivas no Brasil e em Portugal. 4. ed. São Paulo: Cortez, 2006. p. 191-204.

${ }^{20}$ RANGEL, I. C. Pesquisa baseada na ação profissional em ensino. In: NARDI, R. (Org.). Pesquisa em ensino de Ciências e Matemática: ciências e educação. 1996. p.37-43.

${ }^{21}$ PEREIRA, J. M.; HUNGER, D.; SOUZA NETO, S. A relação teoria e prática na formação do bacharel em Educação Física e esporte. In: SOUZA NETO, S.; HUNGER, D. (Org.). Formação profissional em Educação Física: estudos e pesquisas. Rio Claro: Biblioética, 2006. p. 109-119.

Conexões: revista da Faculdade de Educação Física da UNICAMP, Campinas, v. 9, n. 1, p. 166-192, jan./abr. 2011. ISBN: 1983-9030 
${ }^{22}$ HUNGER, D.; FERREIRA, L. A. As diretrizes curriculares nacionais para cursos de graduação em educação física e de licenciaturas. In: SOUZA NETO, S.; HUNGER, D. (Org.). Formação profissional em Educação Física: estudos e pesquisas. Rio Claro: Biblioética, 2006. p. 141-146.

Conexões: revista da Faculdade de Educação Física da UNICAMP, Campinas, v. 9, n. 1, p. 166-192, jan./abr. 2011. ISBN: 1983-9030 